\title{
Microsimulation Evaluation of Eurocode Load Model for American Long-Span Bridges
}

\author{
Bernard Enright \\ Technological University Dublin, bernard.enright@tudublin.ie \\ Colm Carey \\ Technological University Dublin, colm.carey@tudublin.ie \\ Colin Caprani \\ Technological University Dublin, colin.caprani@tudublin.ie
}

Follow this and additional works at: https://arrow.tudublin.ie/engschcivart

Part of the Civil Engineering Commons, and the Structural Engineering Commons

\section{Recommended Citation}

Enright, B., Carey, C., Caprani, C.C. (2013), 'Microsimulation Evaluation of Eurocode Load Model for American Long-Span Bridges', Journal of Bridge Engineering, ASCE, in print, doi:10.1061/(ASCE)BE.1943-5592.0000546

This Article is brought to you for free and open access by the School of Civil and Structural Engineering at ARROW@TU Dublin. It has been accepted for inclusion in Articles by an authorized administrator of ARROW@TU Dublin. For more information, please contact arrow.admin@tudublin.ie, aisling.coyne@tudublin.ie, gerard.connolly@tudublin.ie.

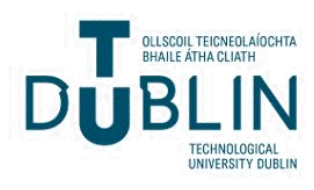




\title{
Microsimulation Evaluation of Eurocode Load Model \\ for American Long-Span Bridges
}

\author{
Bernard Enright ${ }^{\mathrm{a}}$, Colm Carey ${ }^{\mathrm{b}}$, Colin C. Caprani ${ }^{\mathrm{c} *}$ \\ a Lecturer (bernard.enright@dit.ie); ${ }^{\mathrm{b}}$ PhD Researcher, (colm.carey@dit.ie); ${ }^{\mathrm{c}}$ Lecturer, \\ (colin.caprani@dit.ie); *Corresponding Author \\ Dept. of Civil \& Structural Engineering, Dublin Institute of Technology, Bolton St., Dublin 1, Ireland.
}

\begin{abstract}
The ability to accurately predict traffic loading is essential for cost-effective bridge maintenance and repair programs. The traffic load model currently used in the United States for the design of longspan bridges was developed over three decades ago. In the meantime vehicle characteristics and traffic patterns have changed. The Eurocode for traffic loading is more recent, but was calibrated only for bridges up to $200 \mathrm{~m}$ long. In this work, Weigh-In-Motion traffic records from 11 different sites across Alabama are used to establish congested traffic loading. Traffic microsimulation is used to generate the congestion, based on the real traffic data. Influence lines for two typical long-span bridges - one cable-stayed and one suspension bridge - are determined using finite element models. These are used in the microsimulation model to estimate the bridge load effects caused by congested traffic. These results are extrapolated to find characteristic lifetime maximum values which are used to evaluate the Eurocode load model to assess its suitability for long-span bridges. In a similar way, the current American load model for long-span bridges, commonly known as the ASCE model, is evaluated to see if it accurately reflects the congested traffic loading that is currently found on American highways. Recent research has suggested the use of the AASHTO HL-93 load model to estimate the effects of traffic loading on long-span bridges, and this model is also evaluated in this work.
\end{abstract}

\section{CE DATABASE SUBJECT HEADINGS}

Bridge loads, Statistics, Probabilistic models, Traffic, Simulation. 


\section{INTRODUCTION}

Long-span bridges form integral parts of a nation's infrastructure. Maintenance and upkeep of these bridges is costly in terms of both the direct repair costs and the economic loss arising from traffic delays during repairs. In the assessment of any highway bridge structure, live loading is one of the most variable factors; accordingly, its accurate assessment can have a major impact on the rehabilitation needs of the structure. For long-span bridges, the governing form of traffic loading is congested traffic (Buckland et al. 1978; Buckland 1981) and this loading is considered static in nature because the low average speed of the traffic does not generally cause any dynamic loading.

The current American traffic load model, commonly referred to as the ASCE model (ASCE 1981), for long-span bridges - over 500 feet (152.4 m) - was developed in the early 1980s (Buckland 1981). However, both traffic volumes and compositions have changed significantly since the 1980s, and may be expected to continue to do so. In 2005 , heavy trucks made up $8 \%$ of the volume of trucks on U.S. highways, whereas they accounted for only $4 \%$ in the 1990s. According to The Transportation Statistics Annual Report (2006) and AASHTO (2007), loaded trucks travelled 164 billion miles (264 billion $\mathrm{km}$ ) on U.S. roads in 2004 and over the next 30 years this activity is expected to double. In 2007, the average mile of Interstate highway carried 10500 trucks per day (6 525 trucks/km/day) and this is expected to rise to 22700 (14 110) by 2035. This increase in freight traffic may have adverse effects on long-span bridges. The probability of greater numbers of trucks being present on a bridge at a given time may increase as traffic increases and the average weight of these trucks is also likely to rise.

The aim of this work is to examine how well the current American and European load models for normal traffic represent recently-measured American highway traffic on typical long-span bridges. Weigh-in-motion (WIM) measurements of the weights and dimensions of over 21 million trucks taken during 2007 and 2008 at 11 sites in Alabama are used as the basis for comparison with the load models. The weights and dimensions of cars used in this study are taken from measurements taken in Sarnia, Ontario in 1994 and 1995. These collections of vehicle types and data serve as the input for a traffic microsimulation model (Caprani and O'Brien 2008; Caprani 2010). Traffic microsimulation has the ability to reproduce complex traffic phenomena based on drivers' interactions, and is configured to cause the traffic to become congested. The bridge load effects produced by this congested traffic are calculated using various influence lines calculated for idealized models representative of the Golden Gate suspension bridge in San Francisco, CA, and the Sidney Lanier cable-stayed bridge in Brunswick, GA. The calculated load effects are extrapolated to 
estimate maximum lifetime values which are then compared to the Eurocode Load Model 1 (EC LM1). This load model, which is intended to represent all types of normal traffic, was originally calibrated for use on bridges up to $200 \mathrm{~m}$ long and is described in the Eurocode as being conservative for longer bridges (EC1.2 2003). Ratios, $\delta$, of the load model (uniformly distributed load (UDL) and concentrated load) to the actual traffic load effects for long-span bridges is given for both the Eurocode and ASCE code. Recent research (Nowak and Lutomirska 2010) suggests that the HL93 live load specified in AASHTO LRFD (2007) may be suitable for describing traffic loading on longspan bridges. Ratios comparing the HL-93 load model to the actual traffic load effects for long-span bridges are also given.

It should be noted that this work does not compare or comment on the overall levels of safety achieved by differing codes of practice. This would necessitate the inclusion of resistance variables in a full reliability analysis, and this is not done. Instead, only comparison of the actual loading at different return levels is made to those of the different notional load models. However, this comparison is considered meaningful given that loading can be measured and characteristic values estimated both intra- and inter-nationally, leading to improved knowledge for practicing engineers.

\section{TRAFFIC LOAD MODELING}

\section{Background}

Previous modeling of congested traffic has been based on some simplifying and often conservative assumptions. The arrival of successive vehicles has been taken by some authors to be independent and random (Harman et al. 1984; Vrouwenvelder and Waarts 1993; Flint and Neill 1996; EC1.2 2003), whereas others have preserved the recorded arrival process (Ivy et al. 1953; Nowak et al. 2010). A Markov vehicle arrival process based on a transition matrix computed from real traffic is used by Crespo-Minguillon and Casas (1997).

Nowak and Hong (1991) present results based on two alternative possibilities - headways (distance between the back axle of the leading vehicle to the front axle of the following vehicle) between successive vehicles of $15 \mathrm{ft}(4.57 \mathrm{~m})$, and $30 \mathrm{ft}(9.14 \mathrm{~m})$. Vrouwenvelder and Waarts (1993) also use two headway models: a gap of $5.5 \mathrm{~m}$ for a simpler distributed lane load model, and a variable headway of 4 to $10 \mathrm{~m}$ for full congested modeling. A $5 \mathrm{~m}$ headway was used in the background studies to the Eurocode (Bruls et al. 1996; Flint and Jacob 1996). Caprani (2012) uses traffic microsimulation to calibrate normally-distributed gaps (bumper to bumper) in a truck-only traffic stream that replicates the results of different traffic compositions and flow rates. 
Different approaches have been adopted in the modeling of vehicle characteristics, with most of the focus on the modeling of trucks. Truck weights and lengths have either been taken directly from recorded traffic (Ivy et al. 1953; Harman et al. 1984; Nowak et al. 2010), or by creating histograms of truck lengths and weights (Flint and Neill 1986; Crespo-Minguillon and Casas 1997; O'Brien et al. 2010). In contrast, cars and light goods vehicles (LGVs), due to their much lower gross weights, are generally considered to be of less importance. LGVs are represented by a UDL (Harman et al. 1984); by taking the LGV weights and lengths directly from the recorded traffic (Nowak et al. 2010); or by creating a set of standard LGVs (Flint and Neill 1986; Croce and Salvatore 1998, 2001; O’Brien et al. 2010). The weight of cars is disregarded in some studies (Vrouwenvelder and Waarts 1993; Croce and Salvatore 1998, 2001; Nowak et al. 2010) whilst cars are represented as a UDL of $2.0 \mathrm{kN} / \mathrm{m}$ by Harman et al. (1984) and a deterministic car length and a mean car weight is used by others (Buckland et al. 1978, 1981; Flint and Neill 1986; Vrouwenvelder and Waarts 1993; Ditlevsen and Madsen 1997; O’Brien et al. 2010).

Once a traffic model is established and traffic load effects have been calculated, characteristic design values can be obtained by extrapolating the results to a suitable return period, or level of probability (Buckland et al. 1978, 1981; Croce and Salvatore 1998, 2001; O’Brien et al. 2010). For design purposes, it is usual for codes of practice to specify traffic loading in terms of a combination of one or more concentrated loads and an equivalent UDL (EUDL) that together will produce the characteristic load effects (ASCE 1981; EC1.2 2003). Commonly the EUDL is applied only to the loaded length, defined as the total positively contributing length of the influence line to the particular load effect in question (Cremona and Carracilli 1998; Croce and Salvatore 2001).

\section{European Traffic Load Model}

The development of the Eurocode load model is described in Bruls et al. (1996). In its development, to model congested traffic (the governing form of traffic for bridges longer than approximately $30 \mathrm{~m}$ (Bruls et al. 1996)), constant gaps of $5 \mathrm{~m}$ were assumed within an all-truck traffic stream. The trucks were measured on the A6 motorway near Auxerre, France (a two-lane motorway) as it was deemed to represent typical heavy European traffic (Flint and Jacob 1996). The load effects calculated from this model were extrapolated to obtain values with a probability of exceedance of $5 \%$ in 50 years, which is approximately equivalent to a return period of 1000 years. Eurocode Load Model 1 is based on the results of these extrapolations and is intended to cover most of the effects of trucks and cars and is also intended to cover flowing, congested or traffic jam situations with a high percentage of heavy trucks. The load model consists of a tandem (i.e. 2 axles) and a uniformly distributed load 
(UDL) in each lane, as shown in Figure 1 for a carriageway with three notional lanes. The intensity of the loading is greatest in lane 1 , and is lower in the other lanes.

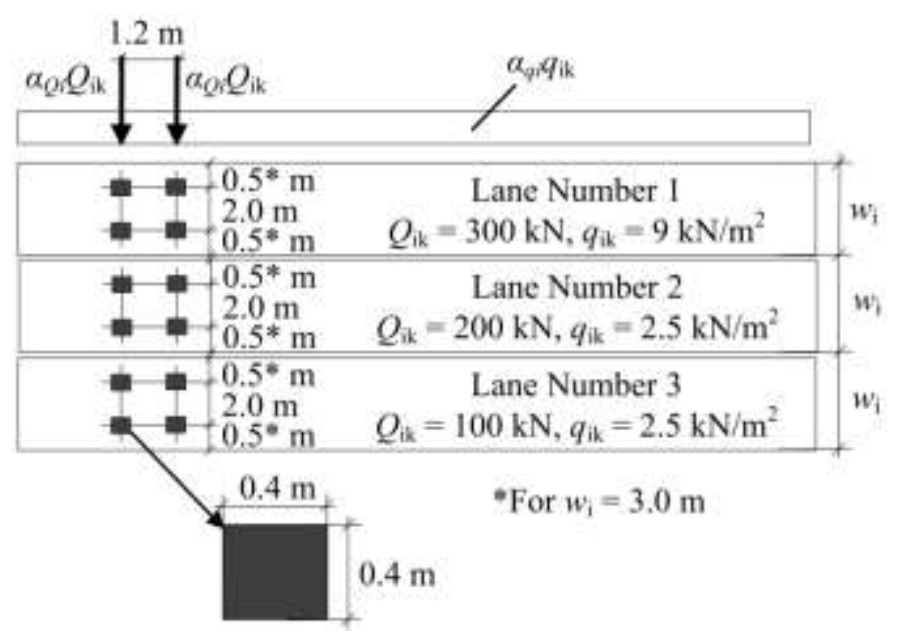

Figure 1. Eurocode Load Model 1 lane loading (EC1.2 2003), where $Q_{\mathrm{ik}}$ is the point load, $q_{\mathrm{ik}}$ is the lane load and $w_{\mathrm{i}}$ is the width of the lanes.

The values for the tandem and the UDL include dynamic amplification, with greater dynamic effects being assumed for shorter bridges (up to $50 \mathrm{~m}$ long). Furthermore, these values may be multiplied by 'adjustment factors' to allow for site-specific situations in each European member state, but for the purposes of this study, these factors are taken as unity. It is noted in the Eurocode that the load models should be used for bridges with loaded lengths less than $200 \mathrm{~m}$, and that Load Model 1 is 'safe-sided' for loaded lengths over 200 m (EC1.2 2003).

\section{American Traffic Load Models}

The current AASHTO code for traffic loading is limited to bridges up to $500 \mathrm{ft}(152.4 \mathrm{~m})$ in length. For longer bridges, AASHTO suggests the use of the American Society of Civil Engineers load model (ASCE 1981). The ASCE load model, which caters for bridges up to $2000 \mathrm{~m}$, was developed by Buckland et al. $(1978,1981)$ and prescribes three levels of traffic loading for different percentages of trucks in the traffic stream. In designing a new bridge, the expected percentage of trucks must be estimated from traffic measurements or otherwise, and the appropriate level of loading chosen. The model consists of a UDL and point load to replicate the effects of traffic loading, as shown in Figure 2. No allowance is made for dynamic loading. The full loading is applied in lane 1 , and a lane factor is used to reduce the loading in the other lanes ( 0.7 for lane 2 and 0.4 for all subsequent lanes). 


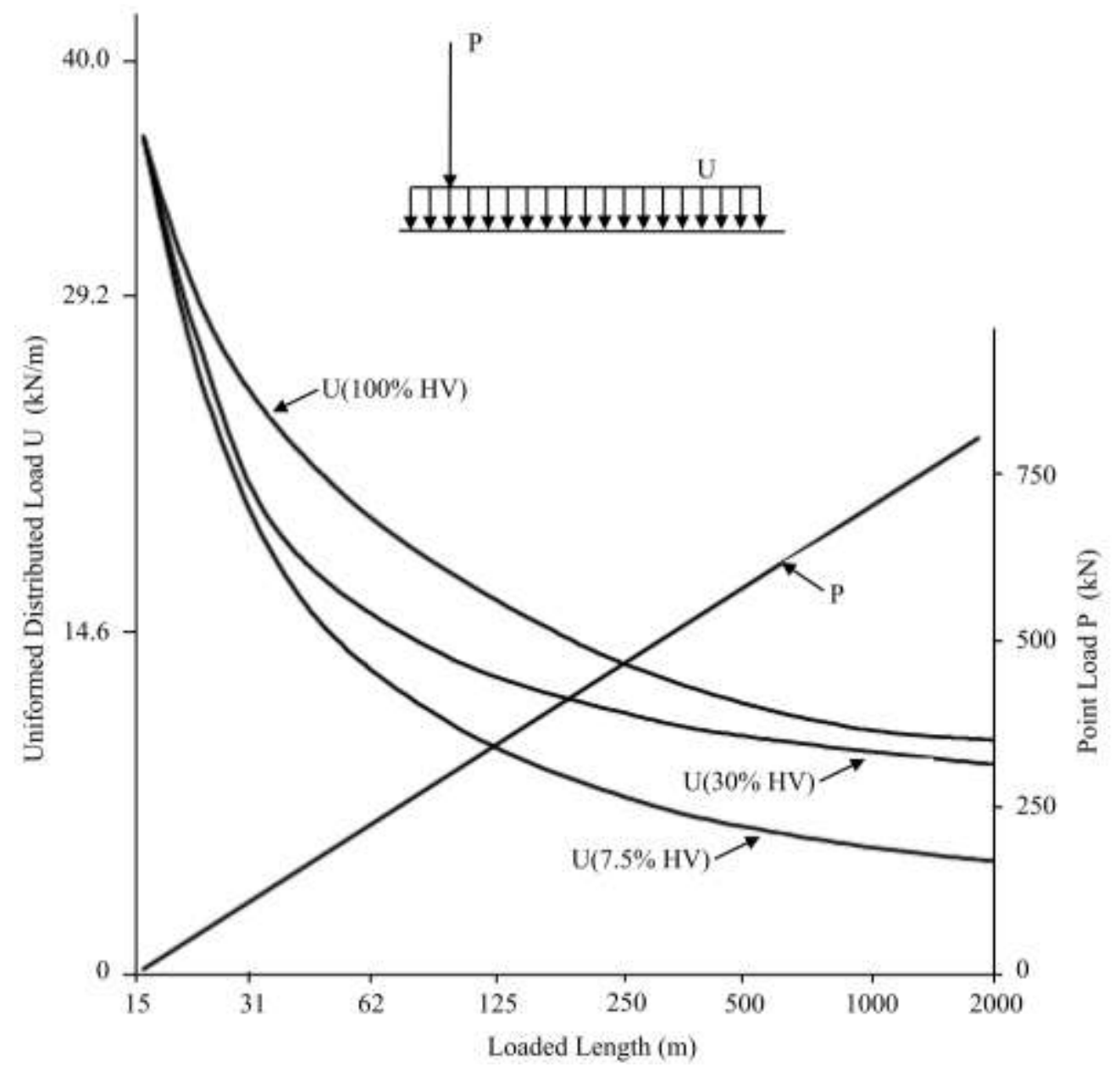

Figure 2. ASCE traffic load model (adapted from Buckland (1981)).

The AASHTO HL-93 load model consists of a three-axle design truck and a $9.3 \mathrm{kN} / \mathrm{m} \mathrm{UDL}$ per lane and is shown in Figure 3 (AASHTO 2007). The axle weights of the design trucks are $35 \mathrm{kN}$ for the front axle, and $145 \mathrm{kN}$ each for the second and third axles. The axle spacing between the first and second axle is set at $4.3 \mathrm{~m}$, and the axle spacing between the second and third axle can vary from 4.3 to 9.0 $\mathrm{m}$. The lane load factors are 1.2, 1.0 and 0.85 for lanes 1,2 , and 3 respectively, and a dynamic application factor of 0.33 is applied to the design truck.

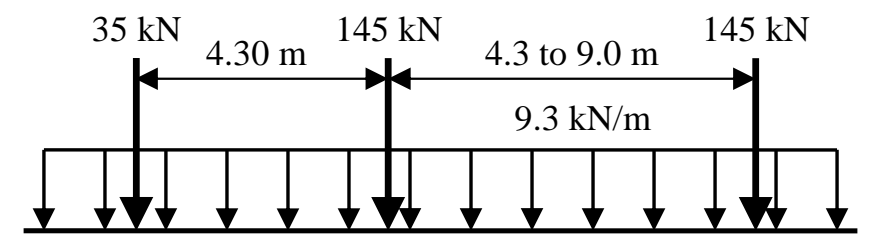

Figure 3. AASHTO HL-93 traffic load model (AASHTO 2007). 


\section{TRAFFIC DATA}

\section{Vehicle Data}

This work uses WIM data obtained at 11 highway sites across the state of Alabama. Up to three lanes of traffic in one direction were measured at each site, with an overall total of 21.3 million trucks recorded. Traffic was recorded in 2007 and 2008, with a full year of traffic data obtained from most sites. Trucks with up to thirteen axles were recorded. The weights and dimensions of cars were not recorded at any of these sites - in this work, cars are defined to be any vehicle with two axles and a gross vehicle weight (GVW) of less than $3.5 \mathrm{t}$, with all other vehicles considered to be trucks. The maximum GVW recorded at any site was 329 t, with 5032 trucks over 80 t, 1992 trucks over $100 \mathrm{t}$, and 8 trucks over $150 \mathrm{t}$, see Table 1. Figure 4(a) shows the percentages of the total traffic at each site represented by trucks over $3.5 \mathrm{t}$ and $5.4 \mathrm{t}$, and Figure 4(b) shows the percentage over 54 t (120 kips).

Table 1. Overview of Alabama traffic

\begin{tabular}{llllllll}
\hline Site & County & Route & Total Trucks & $\begin{array}{l}\text { Average Flow } \\
\text { (Trucks/Day) }\end{array}$ & $\begin{array}{l}\text { No. of } \\
\text { Lanes }\end{array}$ & $\begin{array}{l}\text { Heaviest } \\
\text { Truck (t) }\end{array}$ & $\begin{array}{l}\text { Max } \\
\text { Axles }\end{array}$ \\
\hline 911 & Coosa & US-280 & 853,794 & 3,151 & 2 & 131 & 13 \\
915 & Washington & US-43 & 672,741 & 2,455 & 2 & 110 & 13 \\
918 & Tuscaloosa & I-20/59 & $3,977,019$ & 15,008 & 3 & 130 & 13 \\
931 & Limestone & I-65 & $2,075,533$ & 9,837 & 2 & 85 & 9 \\
933 & Colbert & US-72 & 902,293 & 5,277 & 2 & 92 & 13 \\
934 & Walker & US-78 & $2,132,566$ & 7,783 & 2 & 129 & 13 \\
942 & Montgomery & US-231 & $1,468,043$ & 5,358 & 2 & 300 & 13 \\
960 & Clarke & US-84 & 703,350 & 2,624 & 1 & 126 & 13 \\
961 & Mobile & I-65 & $2,016,143$ & 7,551 & 2 & 136 & 13 \\
963 & Mobile & I-10 & $3,400,750$ & 13,030 & 2 & 136 & 13 \\
964 & Dale & US-231 & 354,357 & 2,272 & 2 & 101 & 13 \\
965 & Macon & I-85 & $2,794,638$ & 10,707 & 2 & 329 & 13 \\
\hline
\end{tabular}

The modeling of the weights and dimensions of cars and light vehicles in this study is based on WIM recordings from Sarnia, Ontario, where details of 50059 cars and light vehicles were recorded in 1994 and 1995. The traffic patterns (i.e. proportions of trucks and cars) modeled in this work are based on the measured traffic classification counts at each of the sites in Alabama. The measurements from Sarnia are used for the sole purpose of representing the weights and dimensions of individual cars more accurately. 


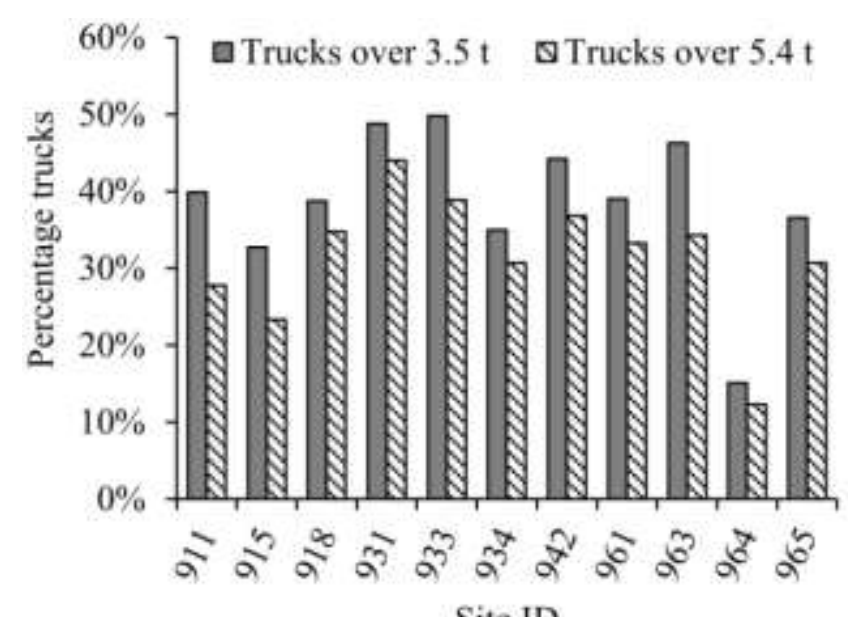

Site ID

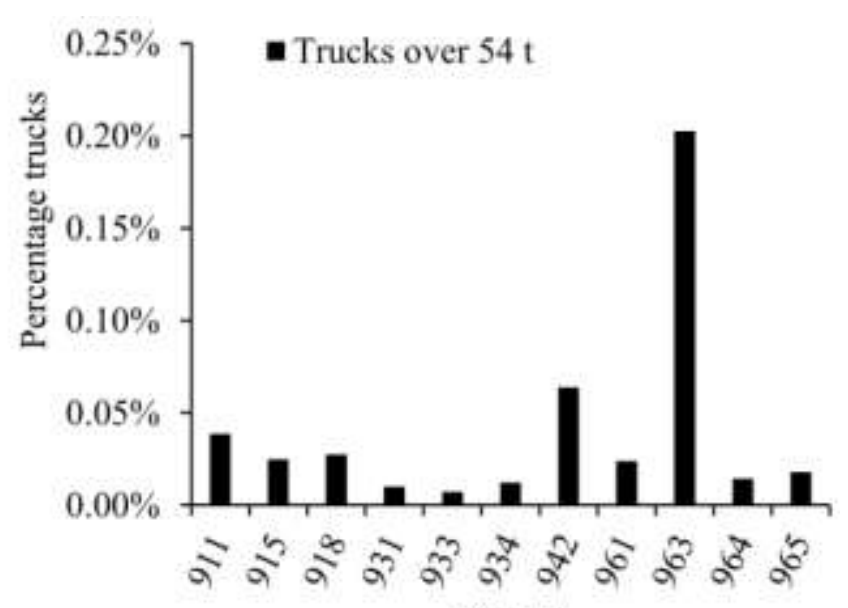

Site ID

Figure 4. Trucks as a percentage of all traffic at the individual Alabama sites (a) for trucks over $3.5 \mathrm{t}$ (EC minimum truck GVW) and $5.4 \mathrm{t}$ (ASCE minimum truck GVW), and (b) trucks over $54 \mathrm{t}$.

Figure 5 shows the truck GVW distribution from the three locations relevant to this work: Vancouver, Canada in 1980 (on which the ASCE load model is based (Buckland 1980)), Auxerre, France in 1986 (on which the Eurocode is based (Flint and Jacob 1996)), and Alabama, United States in 2007 and 2008 (which is the basis of the model presented here). The GVW distributions in Figure 5 help explain why the EC LM1 specifies greater EUDLs than the ASCE model. Even allowing for $100 \%$ trucks in the ASCE load model, the lane 1 loading in EC LM1 is up to twice that of the ASCE model (for bridges over $152.4 \mathrm{~m}$ ), see Figure 1 and 2. Also, the average GVW for the trucks from the Alabama sites in Figure 5 is considerably higher than that of the trucks from Vancouver. This suggests that the ASCE model may underestimate the traffic loading for long-span bridges caused by the traffic from the Alabama sites. Although the maximum truck GVW from the Alabama site ( $329 \mathrm{t}$ ) is considerably greater than that from the Auxerre site $(81.2 \mathrm{t})$ and is probably an abnormal load, individual truck GVWs do not influence traffic load effects significantly for long-span bridges (Buckland 1981; Nowak et al. 2010) since due to the large number of vehicles present on a long-span bridge during maximum loading events, the average truck GVW is of greater importance. The average truck GVW from the Auxerre site is $31.8 \mathrm{t}$ compared to an average truck GVW of $26.8 \mathrm{t}$ from the combined Alabama sites. 


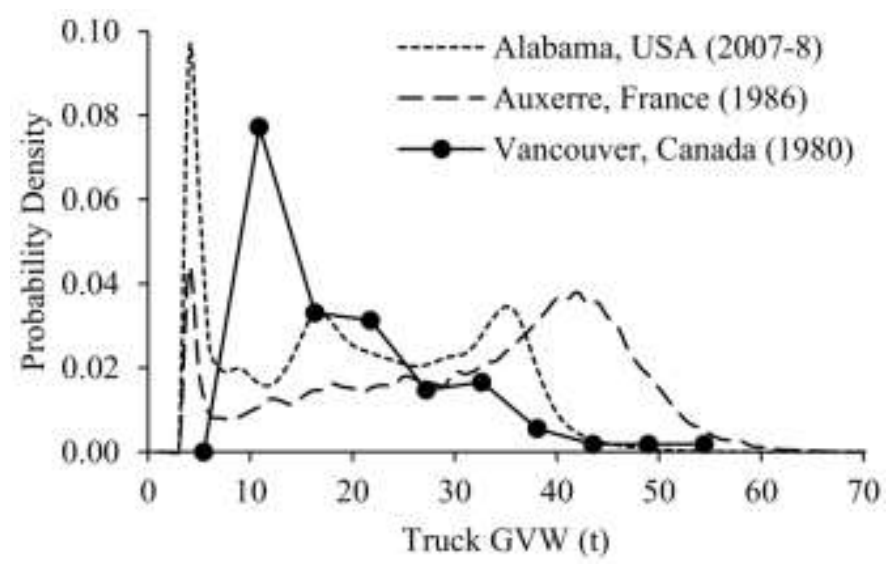

Figure 5. Truck GVW distributions used in developing the ASCE code (Vancouver - for which only limited data is available), the Eurocode (Auxerre), and for this study (Alabama).

\section{Vehicle Overhangs}

For a given set of vehicles, bridge load effects are sensitive to changes in inter-vehicle spacing. For this reason, it is important to represent inter-vehicle gaps (bumper to bumper) correctly in congested traffic loading models (Caprani 2012). The parameters influencing the gap between adjacent front and rear axles are not only those of driving characteristics, but also include the vehicle front and rear overhangs (i.e. distance from the front and rear of the vehicle to the front and rear axles respectively). Previous congested traffic models have used gaps measured from the back axle of the lead vehicle to the front axle to the following vehicle. As vehicle overhangs vary, this adds uncertainty to these models, especially as some vehicles may have back overhangs of up to $4.0 \mathrm{~m}$ (Douglas and Richard 2003). Vehicle overhangs are difficult to measure from loop detectors and are not present in the WIM data used here. Therefore, for this research, overhang information for typical American vehicles are obtained from Douglas and Richard (2003) and AASHTO (2001). These vehicle dimensions are used to categorize vehicles by axle configuration, and front and rear overhangs are added to the WIM data based on each vehicle's axle configuration. 


\section{LONG-SPAN BRIDGE INFLUENCE LINES}

\section{Previous Work}

The choice of influence line is important in the calculation of the characteristic long-span bridge traffic loading. The total load on the bridge (Ivy et al. 1953; Buckland 1981; Vrouwenvelder and Waarts 1993; Cremona and Carracilli 1998; EC1.2 2003; Nowak et al. 2010) is often used to evaluate the effect of traffic on a bridge. Various influence lines have also been used previously including:

- Mid-span bending moment on a simply supported bridge (Buckland 1981; Nowak 1991; Crespo-Minguillon and Casas 1997; Croce and Salvatore 2001; EC1.2 2003; O’Brien et al. 2010);

- Shear at the support of a simply supported bridge (Buckland 1981; Nowak 1991; Ditlevsen 1994; EC1.2 2003);

- Bending moment over the central support of a two-span continuous bridge (Harman et al. 1984; Croce and Salvatore 1998, 2001; EC1.2 2003);

- Maximum and minimum bending moment in a two-span continuous bridge (Harman et al. 1984; EC1.2 2003).

Harman et al. (1994) also used the moment at the first internal support of a three-span continuous bridge, shear at the end support of a three-span continuous bridge, and moment at a fixed external support of a two-span continuous bridge. Many of the above influence lines are also used for shortspan bridges. The main span of a long-span bridge can be over $1 \mathrm{~km}$ long, and the use of influence lines for a simply supported structure may not be appropriate. Some authors have used influence lines that are clearly well-suited to long-span bridges, including:

- Tension in the main cables (Buckland 1991; Ditlevsen 1994; Cremona and Carracilli 1998; Croce and Salvatore 1998);

- Torque in the box girder of a single plane cable-stayed bridge (Buckland 1991; Croce and Salvatore 1998);

- Axial force in the towers (Croce and Salvatore 1998).

\section{Influence Lines Used in this Work}

In this research, influence lines are found for two bridges: a cable-stayed bridge - the Sidney Lanier Bridge in Brunswick, GA, built in 2003; and a suspension bridge - the Golden Gate Bridge in San Francisco, CA, built in 1937. These bridges are chosen as they are representative of typical long-span bridges. The influence lines considered for both bridges are (see Figures 6 and 7):

LE1. $\quad$ Axial force in one of the towers (pylons) $\left(R_{A}\right)$;

LE2. Bending moment at the foot of one of the towers (pylons) $\left(M_{A}\right)$; 
For the Golden Gate bridge:

LE3. Bending moment in the deck at mid-span $\left(M_{B}\right)$;

LE4. Tension force in the main cable $\left(T_{1}\right)$.

For the Sidney Lanier bridge:

LE3. Tension force in Cable $1\left(T_{1}\right)$;

LE4. Tension force in Cable $2\left(T_{2}\right)$.

The two bridges are modeled using finite element analysis and are idealized as plane models for simplicity (Walther et al. 1999). It is assumed that the influence lines used do not vary with the lateral position of each vehicle (i.e. the lane in which the vehicle is traveling). Further, the influence lines are approximate: the geometric and material data for the models are found from various literature sources (Podolny 1999; Sameul 2007; Finley 2005; PCI 2005). Where explicit information is not available, estimates are used, informed by similar materials or bridges. Some of the assumptions used in modeling the bridges include: the saddle on top of the towers in both bridges is taken to be fixed in the vertical direction and free in the horizontal direction; the towers in the Golden Gate Bridge are considered to be linearly tapered for simplicity; and the deck in both bridges is considered to be simply supported in the lateral direction. In any case, it is the relative values of load effects that are of interest here, so it is only necessary to approximate the shape of the influence line. An exact result appropriate for the assessment of these specific bridges is not sought.

\section{Sidney Lanier Bridge}

Figure 6(a) shows the front elevation of the model developed for the Sidney Lanier Bridge. The total length of the bridge is $2371 \mathrm{~m}$, with a main span of $381 \mathrm{~m}$. The concrete deck is $300 \mathrm{~mm}$ deep, and is supported by two longitudinal reinforced concrete edge girders $1.5 \mathrm{~m}$ deep by $1.4 \mathrm{~m}$ wide. The bridge is supported by two $142 \mathrm{~m}$ high $\mathrm{H}$-frame towers consisting of hollow rectangular columns connected at two locations by cross-ties, with $600 \mathrm{~mm}$ thick reinforced concrete walls throughout. The tower columns are $6.4 \mathrm{~m}$ deep (in the longitudinal direction) and their width (in the transverse direction) reduces linearly from $7.6 \mathrm{~m}$ at the base to $2.7 \mathrm{~m}$ at deck level, and remains constant from there on. There are two planes of stay cables in a double-fan configuration supporting the deck edge girders. The cables are of different diameters, ranging from $140 \mathrm{~mm}$ for the shorter cables up to $225 \mathrm{~mm}$ for the longest. The influence lines found for the load effects used in this work are shown in Figure 6(b). 


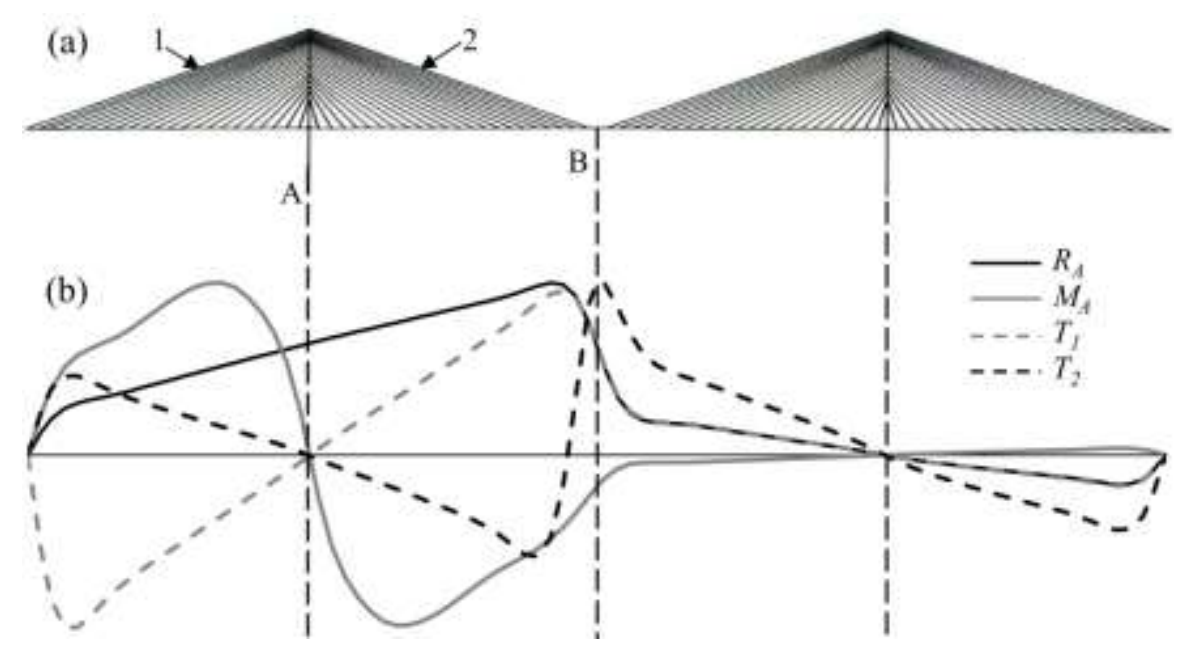

Figure 6. The Sidney Lanier Bridge: (a) elevation and (b) influence lines (see the main text for definitions of the terms).

\section{Golden Gate Bridge}

Figure 7(a) shows an elevation of the Golden Gate Bridge model developed for this work. The total length of the bridge is $2737 \mathrm{~m}$; the main span is $1280 \mathrm{~m}$ long. The deck is supported by a $7.6 \mathrm{~m}$ deep steel truss, with a $600 \mathrm{~mm}$ deep top and bottom chord. The towers are $227 \mathrm{~m}$ tall, with $152 \mathrm{~m}$ above the deck. The tower legs are steel hollow box sections with varying dimensions: from $16 \mathrm{~m}$ longitudinally and $10 \mathrm{~m}$ transversely at the base, to $7 \mathrm{~m}$ and $3 \mathrm{~m}$ respectively at the top of the tower, and are assumed to have a constant thickness of $140 \mathrm{~mm}$. The main cable is $900 \mathrm{~mm}$ diameter and catenary in shape (Freeman 1925). The vertical suspenders are $70 \mathrm{~mm}$ in diameter and spaced at $15.2 \mathrm{~m}$. Figure 7(b) shows the influence lines for this work found using the model.

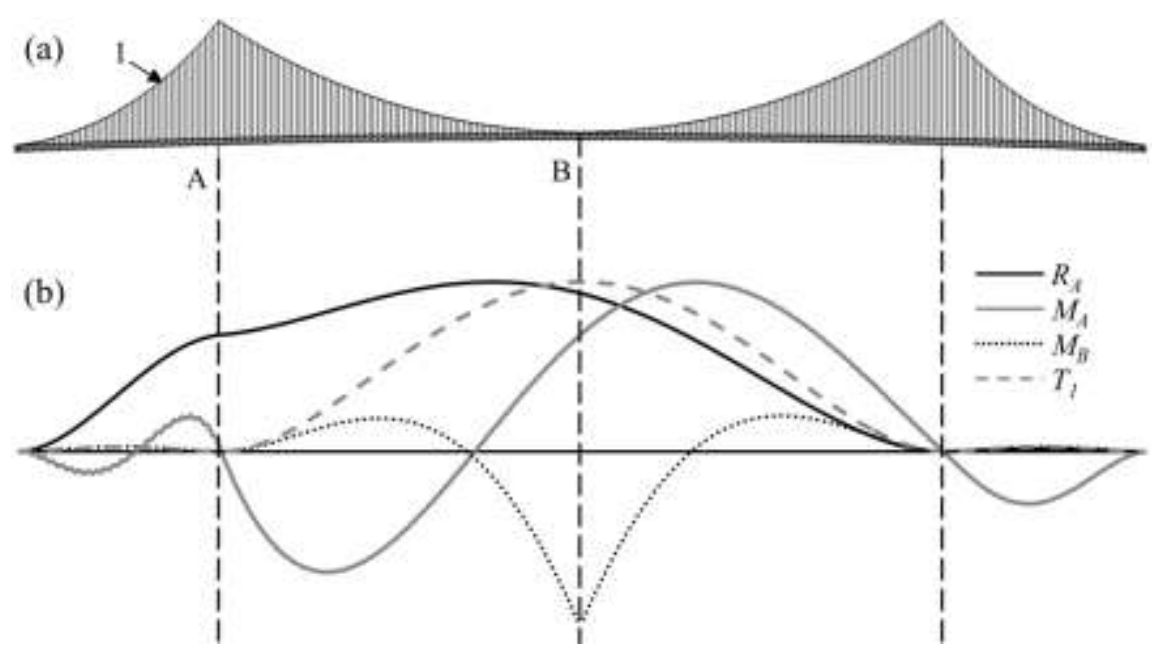

Figure 7. The Golden Gate Bridge: (a) elevation and (b) influence lines (see the main text for definitions of the terms). 


\section{TRAFFIC MICROSIMULATION AND LOAD EFFECTS}

\section{Microsimulation Model}

Microsimulation is used here to induce congestion in the free-flowing WIM traffic data. A computer program, Simba (Simulation for Bridge Assessment - see Caprani and O'Brien 2008; Caprani 2010; Caprani 2012), based on the Intelligent Driver Model (IDM) developed by Treiber and others (Treiber et al. 2000a, b) is used in this work. The model is based on a continuous function of acceleration and deceleration components which describes the longitudinal motion of an individual vehicle in response to its surroundings, given some physically meaningful mechanical and driver performance parameters. In particular, the IDM is based on the idea that a driver tries to minimize braking decelerations. The acceleration a vehicle undergoes is defined by:

$$
\frac{d v}{d t}=a\left[1-\left(\frac{v}{v_{0}}\right)^{4}-\left(\frac{s^{*}(v, \Delta v)}{s}\right)^{2}\right]
$$

where: $v$ is the velocity of the vehicle; $v_{0}$ is its desired velocity; $s$ is the gap to the lead vehicle; and $\Delta v$ is the velocity difference (approaching rate) to the lead vehicle. The desired gap, $s^{*}$, is calculated using:

$$
s^{*}(v, \Delta v)=s_{0}+s_{1} \sqrt{\frac{v}{v_{0}}}+T v+\frac{v \Delta v}{2 \sqrt{a b}}
$$

where: $s_{0}$ is the minimum jam distance; $s_{1}$ is an 'elastic' jam distance; $T$ is the safe time headway; $a$ is the maximum acceleration; and $b$ is the comfortable deceleration. The lane changing model MOBIL is used for this work, as described by Kesting et al. (2007). The parameters used in this work are taken from Helbing et al. (2002) and Kesting et al. (2007) and are given in Table 2. 
Table 2. IDM parameter values used in the microsimulation model

\begin{tabular}{lll}
\hline Parameter & Car & Truck \\
\hline Safe time headway, $T(\mathrm{~s})$ & 1.2 & 1.7 \\
Maximum acceleration, $a\left(\mathrm{~m} / \mathrm{s}^{2}\right)$ & 0.8 & 0.4 \\
Comfortable deceleration, $b\left(\mathrm{~m} / \mathrm{s}^{2}\right)$ & 1.25 & 0.8 \\
Minimum jam distance, $s_{0}(\mathrm{~m})$ & 1 & 1 \\
Elastic jam distance, $s_{1}(\mathrm{~m})$ & 10 & 10 \\
Desired Velocity, $v_{0}(\mathrm{~km} / \mathrm{h})$ & $120( \pm 20)$ & $80( \pm 20)$ \\
Lane change politeness factor, $p$ & 0.25 & 0.25 \\
Outside lane bias factor & 0.3 & 0.3 \\
Lane change threshold $\left(\mathrm{m} / \mathrm{s}^{2}\right)$ & 0.1 & 0.1 \\
\hline
\end{tabular}

\section{Traffic Flow Modeling and Load Effect Calculation}

The WIM measurements for trucks and cars described earlier provide the initial traffic stream input for the microsimulation. For each of the Alabama sites, trucks are selected randomly from the WIM data, and cars are added so as to replicate the recorded percentage of trucks at the site. The percentage of trucks is calculated to be consistent with the ASCE model (i.e. where trucks are defined to be vehicles weighing more than 12 kips $(5.4 \mathrm{t})$ ). The initial distribution of trucks between the lanes at each site is the same as the recorded proportions of trucks in each lane at that site. The traffic is modeled using microsimulation and load effects are calculated for the influence lines for both bridges separately.

The traffic in the WIM data is free-flowing, and the microsimulation model described earlier is used to produce the congested traffic suitable for critical long-span bridge loading scenarios. An input flow rate of 1000 vehicles per hour is used in lane 1, with pro-rata flows in the other lanes. Three hours of input traffic is generated for each site and this produces two hours of congested traffic at the beginning of the virtual bridge, as described below. Assumptions made with regard to the arrival process and initial inter-vehicle gap distribution dissipate after the traffic is passed through the first few kilometers of microsimulation (Carey et al. 2012). 
For the traffic microsimulation, a virtual road of $10 \mathrm{~km}$ is used. It is assumed that loading is symmetrical about the center line of the roadway and is carried by the cable system on that side of the bridge. Therefore only one direction is modeled, with a two-lane road for the Sidney Lanier Bridge, and a three-lane road for the Golden Gate Bridge. To induce congested traffic on the virtual road, a severe flow-restriction, or bottleneck, is added between 9.5 and $10 \mathrm{~km}$. To implement the bottleneck, each vehicle's desired velocity is changed to $20 \mathrm{~km} / \mathrm{h}$ and safe time headway increased by $0.5 \mathrm{~s}$. This arrangement induces Homogeneous Congested Traffic (HCT) which is characterized by a low average velocity but, in contrast to fully jammed traffic, has relatively high traffic flow (Helbing et al. 2002). A virtual bridge, with the associated influence lines, is placed so that it ends $500 \mathrm{~m}$ before the start of the bottleneck. In this manner, transient congested conditions are avoided and the bridge experiences the most severe form of congestion.

It is assumed that two hours of congested traffic represents the daily recurrent congestion conditions on the bridge. The load effects caused as this congested traffic crosses the bridge are calculated and the maximum values for each influence line in each day are noted. The traffic and load effects for each day are considered to be independent and identically distributed. In all, load effects for over one year of congested traffic are obtained from the microsimulation for each of the 11 sites and for both bridges.

The Generalized Extreme Value distribution (Coles 2001) is used to extrapolate the daily maximum load effects for each scenario considered. It is given by:

$$
G(s)=\exp \left\{-\left[1-\xi\left(\frac{s-\mu}{\sigma}\right)\right]_{+}^{1 / \xi}\right\}
$$

where $[h]_{+}=\max (h, 0)$ and $\mu, \sigma, \xi$ are the location, scale, and shape parameters respectively. The load effect results for each scenario are extrapolated to determine a characteristic value, $S^{*}$. A 1000 -year return period (corresponding to approximately $5 \%$ probability of exceedance in 50 years) was used for the EC LM1 for design (Bruls et al. 1996), a 5-year return period was used by Buckland (1981) in creating the ASCE model and a 75-year return period for the AASHTO HL-93 load model (AASHTO 2007). The characteristic values, $S^{*}$, corresponding to all of these return periods are found. 


\section{EVALUATION RESULTS}

\section{Basis of Comparison}

The ASCE, EC LM1, and AASHTO HL-93 load models are defined as a combination of a concentrated load (point, tandem, or truck load, respectively) and a distributed load that together represent the effects of traffic loading. For each code of practice, the characteristic load effect is determined by applying the concentrated load $\left(P_{E C}, P_{A S C E}\right.$ and $\left.P_{H L-93}\right)$ and total UDL across all lanes $\left(w_{E C}, w_{A S C E}\right.$ and $\left.w_{H L-93}\right)$ to the bridge. The concentrated load of each code is applied at the location that results in the largest load effect for each influence line and the UDL is not applied to those sections of the bridge where it would reduce the load effect. The resulting target characteristic values are denoted $S_{E C}$, $S_{A S C E}$, and $S_{H L-93}$.

The daily maximum load effects found from the microsimulation are extrapolated to characteristic values, $S^{*}$, and these values are then directly comparable to the characteristic values of each code, $S_{E C}, S_{A S C E}$ and $S_{H L-93}$, through a ratio as follows:

$$
\delta_{C}=\frac{S^{*}}{S_{C}} \quad C \in\{\mathrm{EC}, \text { ASCE, HL-93 }\}
$$

This process is repeated for each influence line for both bridges for all sites. Note that $w_{E C}$ is taken directly from the Eurocode, and no adjustment is made for any dynamic amplification included in EC LM1.

\section{Results}

Using the preceding methodology, the results are shown in Figure 8(a) for the Eurocode model, Figure $8(\mathrm{~b})$ for the ASCE model, and Figure 8(c) for the AASHTO HL-93 model. This shows the $\delta_{C}$ factors for the traffic at each site for the four different influence lines for the two bridges. The upper bound for each site is also shown (as a dotted line). It can be seen that the EC traffic load model overestimates $\left(\delta_{E C}<1.0\right)$ the traffic loading for all sites, with the most lightly-loaded site having a maximum $\delta_{E C}$ value of just 0.54 (LE4 - GGB). 

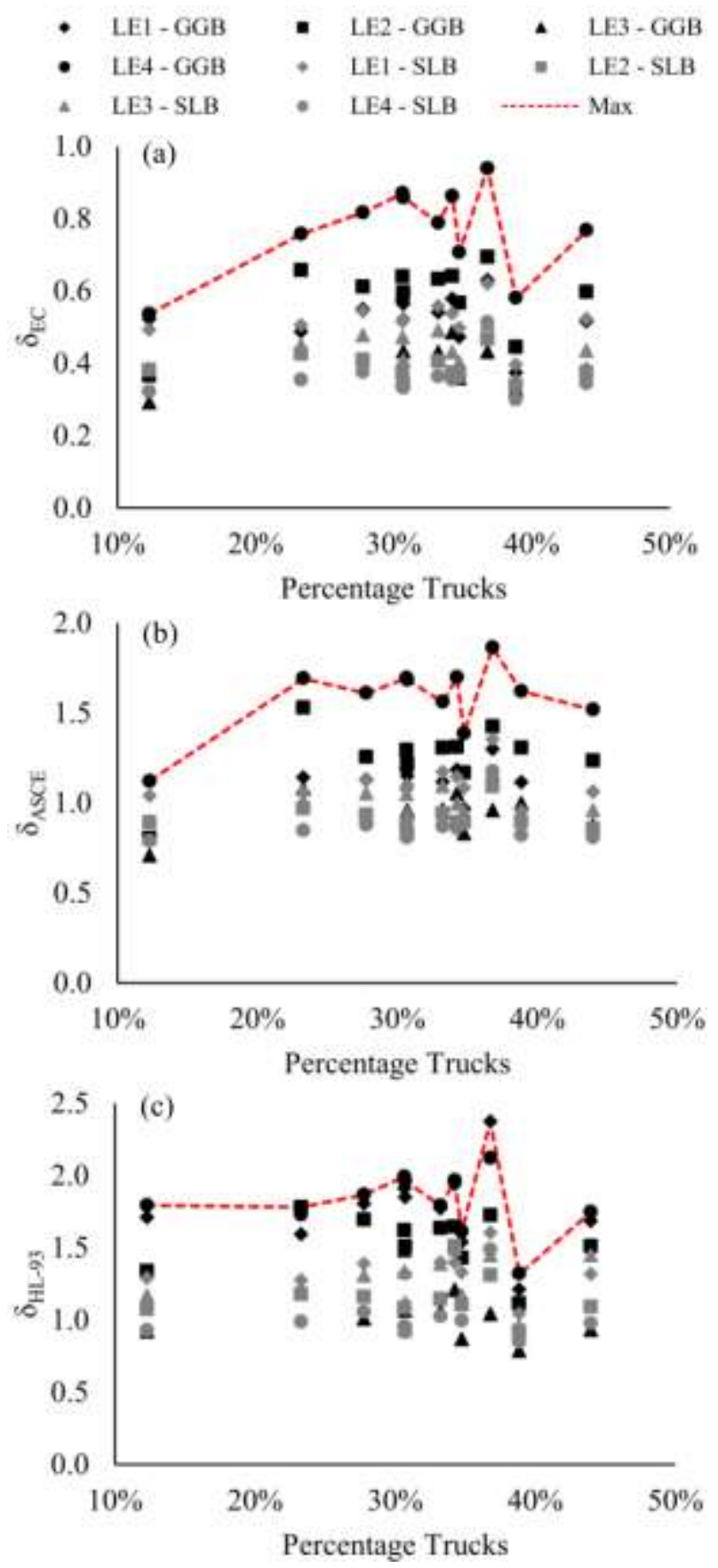

Figure 8. Ratios of load model UDLs to actual traffic on long-span bridges for different influence lines (LE1-4) and sites (by truck percentage): (a) Eurocode Load Model 1 ( $\left.\delta_{\mathrm{EC}}\right)$; (b) ASCE load model $\left(\delta_{\mathrm{ASCE}}\right)$; (c) AASHTO HL-93 load model $\left(\delta_{\mathrm{HL}-93}\right)$. (Note: GGB=Golden Gate Bridge; SLB=Sidney Lanier Bridge)

It should be noted that the EC load model does not vary for different percentages of trucks. However, the Eurocode is always conservative and does match reasonably well the loading for some sites and influence lines. In contrast, Figure 8(b) shows that the ASCE model underestimates $\left(\delta_{A S C E}>1.0\right)$ the traffic loading significantly, with a maximum $\delta_{\text {ASCE }}$ value of 1.86 at the most heavilyloaded site. Figure 8(c) shows that the AASHTO HL-93 model also underestimates the traffic loading, 
with the maximum $\delta_{\mathrm{HL}-93}$ value of 2.37 which also occurs at the most heavily-loaded site. For both bridges, tension in the cables gives the highest ratios for all truck percentages considered for the Eurocode and ASCE models: in the main cable for the Golden Gate Bridge; and in cable 2 for the Sidney Lanier Bridge (Figure 6). For the HL-93 model the axial force in the main tower gives the highest ratio. Further, the ratios for the Golden Gate Bridge are, in most cases, greater than those from the Sidney Lanier Bridge, despite the same traffic being used on both bridges.

The truck GVW distribution used here, recorded in Alabama in 2007 and 2008, is considerably different to that used by Buckland et al. $(1978,1980)$ in the development of the ASCE load model (Figure 5). The increased number of trucks of high GVW in the WIM data is a significant contributory factor in the calculation of the ratios. While load effect roughly increases with truck percentage, the GVW distribution appears to be much more important. For example, site 933 has $39 \%$ trucks (see Figure $4(\mathrm{a}))$, and has a $\delta_{\mathrm{EC}}$ of 0.58 , whereas site 942 has $37 \%$ trucks but a $\delta_{\mathrm{EC}}$ of 0.94 . This much larger $\delta_{\mathrm{EC}}$ value can be attributed to the fact that site 942 has 6 times the amount of trucks over $54 \mathrm{t}$ compared with site 933 (see Figure 4(b)).

For design purposes load factors are applied to traffic loading in the Eurocode (1.35) and AASHTO LRFD (1.75). For the ASCE load model a load factor of 1.8 is used, as was the case in the design of the Alex Fraser Bridge (Buckland 1991). These load factors are not applied to the load models used here. The comparisons in Figure 8 (i.e. the $\delta$ factors) are based on nominal or characteristic loading as described in the relevant codes. The results given do not provide a direct measure of the safety of bridges designed to these codes because no account has been taken of the resistance side factors, which differ in each code.

Finally, the large variation in ratios for different load effects and sites indicates the benefit of using a site-specific load model in the assessment of an existing structure. Indeed, the low ratios for some load effects mean that unnecessary repairs may be instigated if a general load model is used. 


\section{CONCLUSIONS}

This research presents a methodology for determining traffic load effects on long-span bridges. Finite element models are used to calculate influence lines representative of long-span bridges. Recorded traffic data, consisting of over 21 million trucks from 11 sites in Alabama, and approximately 50000 cars from a site in Ontario, is used in traffic microsimulation to obtain load effects under congested conditions. Load effects representing over one year of traffic are obtained and extrapolated to 5-year and 1000-year return periods, and equivalent UDLs are calculated based on the load models in design codes. The intensity of these EUDLs is compared with the current EC LM1, ASCE load models, and the AASHTO HL-93 model. The EC LM1 load model is found to be on the safe side for the long-span bridges and sites studied. In contrast, the ASCE model and the AASHTO HL-93 model are found to underestimate loading significantly for some sites and influence lines.

Freight traffic is expected to increase in volume over the next few decades, with greater numbers of fully-loaded trucks travelling on American highways. The traffic load results presented here do not account for these future traffic trends and hence may underestimate future traffic loading. To cater for this possibility, the approach presented here could be carried out at regular intervals using updated traffic data, to ensure bridge safety.

The results presented here are subject to the assumptions made for this work. However, whilst different results may be found for other bridges and traffic streams, it does appear that the Eurocode may find good applicability in the design and assessment of North American highway infrastructure. Further, the overall methodology suggested here can be used for a detailed bridge assessment, and could result in significant savings since the application of overly conservative loading models can increase the regularity and severity of possibly unnecessary bridge repair programs.

\section{ACKNOWLEDGMENTS}

The authors would like to acknowledge the Dublin Institute of Technology ABBEST Scholarship Programme for funding this research, and also the Alabama Department of Transportation and the Ontario Ministry of Transportation for supplying the WIM traffic data. 


\section{REFERENCES}

AASHTO (2007), "America's Freight Challenge", American Association of State Highway and Transportation Officials, Washington, DC.

ASCE Committee on Loads and Forces on Bridges (1981), "Recommended Design Loads for Bridges", ASCE Journal of Structural Engineering, 107 (7): 1161-1213.

American Association of State Highway and Transportation Officials (2001), "A Policy on Geometric Design of Highways and Streets", Washington, DC.

Buckland, P.G., McBryde, J.P. and Francis, P.D. (1978), "Traffic loading of long span bridges", Conference on bridge engineering proceedings, Transportation Record Research, 146-154.

Buckland, P.G. (1981), "Recommended design loads for bridges (Committee on loads and forces on bridges of the committee on bridges of the structural division)", ASCE Journal of the Structural Division, ASCE, 1161-1213.

Buckland, P.G. (1991), "North American and British Long-Span Bridge Loads", ASCE Journal of Structural Engineering, 117(10), 2972-2987.

Bruls, A., Croce, P., Sanpaolesi, L. and Sedlacek, G. (1996), "ENV1991 - Part 3: Traffic Loads on Bridges; Calibration of Load Models for Road Bridges", Proceedings of IABSE Colloquium, Delft, The Netherlands, IABSE-AIPC-IVBH, 439-453.

Caprani, C.C. and OBrien, E.J. (2008), "The governing form of traffic for highway bridge loading", Proceedings of 4th Symposium on Bridge and Infrastructure Research in Ireland, E. Cannon, R. West, P. Fanning (Eds.), National University of Ireland, Galway, 53-60.

Caprani, C.C. (2010), "Using Microsimulation to Estimate Highway Bridge Traffic Load", Proc. 5th Intl. Conf. on Bridge Maintenance, Safety and Management, IABMAS, Philadelphia.

Caprani, C.C. (2012), "Calibration of a congestion load model for highway bridges using traffic microsimulation", Structural Engineering International, 22(3), 342-348.

Carey, C., Caprani, C.C. and Enright, B. (2012), "Reducing traffic loading on long-span bridges by means of lane-changing restrictions", Proceedings of Bridge and Concrete Research in Ireland, Dublin, 331-336.

Coles, S.G. (2001), "An Introduction to Statistical Modelling of Extreme Values", London: SpringerVerlag.

Cremona C., and Carracilli, J. (1998), "Evaluation of extreme traffic loads effects in cable stayed and suspension bridges by use of WIM records", Proc. 2nd Eur. Conf. on Weigh-in-Motion of Road Vehicles, 243-251.

Crespo-Minguillón, C. and Casas, J.R. (1997), “A Comprehensive traffic load model for bridge safety checking", Structural Safety, 19, 339-359. 
Croce, P. and Salvatore, W. (1998), "Stochastic modelling of traffic loads for long-span bridges", IABSE Symp., Long-Span and High-Rise Structures, Kobe, 427-434.

Croce, P. and Salvatore W. (2001), "Stochastic model for multilane traffic effects on bridges", Journal of Bridge Engineering, vol.6, 136-143.

Ditlevsen, O. and Madsen, H. (1997), "Stochastic vehicle-queue-load model for large bridges", Journal of Engineering Mechanics, 120 (9), 1829-1847.

Douglas, W.H., and K. R. Richard (2003), "Review of Truck Characteristics as Factors in Roadway Design", NCHRP Report 505, Transportation Research Board of the National Academics, Washington, D.C.

EC1.2, Eurocode 1: Actions on Structures, Part 2 (2003): "Traffic loads on bridges", European Standard EN 1991-2: European Committee for Standardisation, Brussels.

Enright, B., Carey, C. and Caprani, C.C. (2012), "The Effect of Lane Changing on Long-Span Highway Bridge Traffic Loading", Proc. 6th Intl. Conf. on Bridge Maintenance, Safety and Management, IABMAS, Italy.

Finley, R.C. (2005), "Sidney Lanier Bridge Receives Honor Award," Segments, American Segmental Bridge Institute, Volume 46, Spring 2005, 4-5.

Flint and Neill Partnership for TRRL (1986), "Interim design standard: long span bridge loading”, Transport and Road Research Laboratory: Crowthorne (Contractor Report 16).

Flint, A.R. and Jacob, B.A. (1996), "Extreme traffic loads on road bridges and target values for their effects for code calibration", Proceedings of IABSE Colloquium, Delft, The Netherlands, IABSEAIPC-IVBH, 469 - 478.

Freemen, I. (1925), "A general form of the suspension bridge catenary", Bulletin of American Mathematical Society, 31 (8), 425-429.

Harman, D.J., Davenport, A.G. and Wong, W.S.S. (1984), "Traffic loads on medium and long-span bridges", Canadian Journal of Civil Engineering, v11, n3, 556-573.

Helbing, D., Hennecke, A., Shvetsov, V. and Treiber, M. (2002), "Micro- and macrosimulation of freeway traffic", Mathematical and Computer Modelling, 35(5/6), 517-547.

Ivy, R.J., Lin, T.Y., Mitchell, S., Raab, N.C., Richey, V.J. and Scheffey, C.F. (1953), "Live loading for longspan highway bridges", ASCE Trans., Paper No. 3708, 119: 981-1004.

Kesting, A., Treiber, M. and Helbing, D. (2007), “General lane-changing model MOBIL for carfollowing models", Transportation Research Record: Journal of the Transportation Research Board, Volume 1999/2007, 86-94.

Nowak, A.S. and Hong, Y.K. (1991), "Bridge live load models", Journal of Structural Engineering, ASCE, 117(9), 2757-2767. 
Nowak, A.S., Lutomirska, M. and Sheikh Ibrahim, F.I. (2010), "The development of live load for longspan bridges", Bridge Structures - Assessment, Design \& Construction, Volume 6, Number 1-2, 73-79.

OBrien, E.J., Hayrapetova, A. and Walsh, C. (2010), "The use of micro-simulation for congested traffic load modelling of medium- and long-span bridges", Structure and Infrastructure Engineering, 269-276.

Podolny, W. Jr. (1999), "Section 15: Cable-Suspended Bridges - Structural Steel Designer's Handbook", 3rd Ed., McGraw-Hill, Columbus, USA.

Precast/Prestressed Concrete Institute (PCI) (2005), "Sidney Lanier Bridge", <http://www.gcpci.org/index.cfm/applications/infrastructure> (Jun 2012).

Sameul, K. F. (2007), "The Study on San Francisco Golden Gate Bridge", Proceedings of Bridge Engineering 2 Conference, University of Bath, Bath, UK.

Transportation Statistics Annual Report (2006), U.S. Department of Transportation, Bureau of Transportation Statistics.

Treiber, M., Hennecke, A. and Helbing, D. (2000), "Microscopic Simulation of Congested Traffic", Traffic and Granular Flow'99, Helbing, D., Herrmann, H.J., Schreckenberg, M., and Wolf, D.E. (Eds.), Springer, Berlin, 365-376.

Treiber, M., Hennecke, A. and Helbing, D. (2000), “Congested Traffic States in Empirical Observations and Microscopic Simulations", Physical Review E, 62(2), 1805-1824.

Vrouwenvelder, A.C.W.M. and Waarts P.H. (1993), "Traffic loads on bridges", Structural Engineering International, 3/93, 169-177.

Walther, R., Houriet, B., Isler, W., Moia, P. and Klein, J. F. (1999), “Cable-stayed bridges”, $2^{\text {nd }}$ Ed., Thomas Telford Ltd., London, UK. 